\title{
Missing Wrists in a Patient with Rheumatoid Arthritis: A Matter of Compliance
}

FRANZ WEGNER, MD, Junior Resident, University of Giessen, Department of Rheumatology and Clinical Immunology, Kerckhoff Clinic; ULF MÜLLER-LADNER, MD, PhD, Professor, Head of Department, University of Giessen, Department of Rheumatology and Clinical Immunology, Kerckhoff Clinic; FLORIAN M.P. MEIER, MD, Specialist Trainee, University of Giessen, Department of Rheumatology and Clinical Immunology, Kerckhoff Clinic, Bad Nauheim, Germany. Address correspondence to Dr. U. Müller-Ladner, Benekestrasse 2-8, 61231 Bad Nauheim, Germany. E-mail: u.mueller-ladner@kerckhoff-klinik.de. J Rheumatol 2017;44:655; doi:10.3899/jrheum.161044. No ethics board approval was required, in accordance with University of Giessen policy.

Rheumatoid arthritis (RA) is the most common autoimmune joint disease. Tight disease control and major advances in therapy have led to significant improvement in outcomes of this disease. Nevertheless, we came across unusual findings revealing severe consequences of patients' noncompliance ${ }^{1}$.

A 66-year-old, right-handed former seamstress with a history of RA since 2006 had started receiving monotherapy with tocilizumab in 2012, but did not show up at our outpatient department for 3 years and had only irregular infusions during that time. Now, she presented with a severe loss of function and pain in hands, knees, and elbows, and an unusually shortened carpal region. Laboratory results showed elevated levels of C-reactive protein (CRP; $2.0 \mathrm{mg} / \mathrm{dl}$ ), erythrocyte sedimentation rate $(56 \mathrm{~mm} / \mathrm{h})$, rheumatoid factor $(1418 \mathrm{U} / \mathrm{ml})$, and antibodies to citrullinated protein antigens (> $200 \mathrm{U} / \mathrm{ml}$ ). Arthrosonography revealed strong inflammatory activity. Plain radiographs of both hands showed progressive erosive disease with severe destruction of nearly all joints, especially when compared with radiographs taken
3 years ago (Figure 1A), including a complete lysis of the right and most parts of the left carpus (Figure 1B). Subsequently, we initiated therapy with rituximab (RTX) because of facilitated therapy monitoring and antibody status $^{2}$. After 4 months, good clinical response was reported. Because CRP levels increased again, the next cycle with RTX was planned. The case illustrates the aggressive character of RA, which can result in destruction of hand joints, especially if not monitored and treated on a regular basis ${ }^{3}$.

\section{REFERENCES}

1. Smolen JS, Aletaha D, McInnes IB. Rheumatoid arthritis. Lancet 2016;388:2023-38.

2. van Vollenhoven RF, Fleischmann RM, Furst DE, Lacey S, Lehane PB. Longterm safety of rituximab: final report of the Rheumatoid Arthritis Global Clinical Trial Program over 11 years. J Rheumatol 2015;42:1761-6.

3. Gadallah MA, Boulos DN, Gebrel A, Dewedar S, Morisky DE. Assessment of rheumatoid arthritis patients' adherence to treatment. Am J Med Sci 2015;349:151-6.
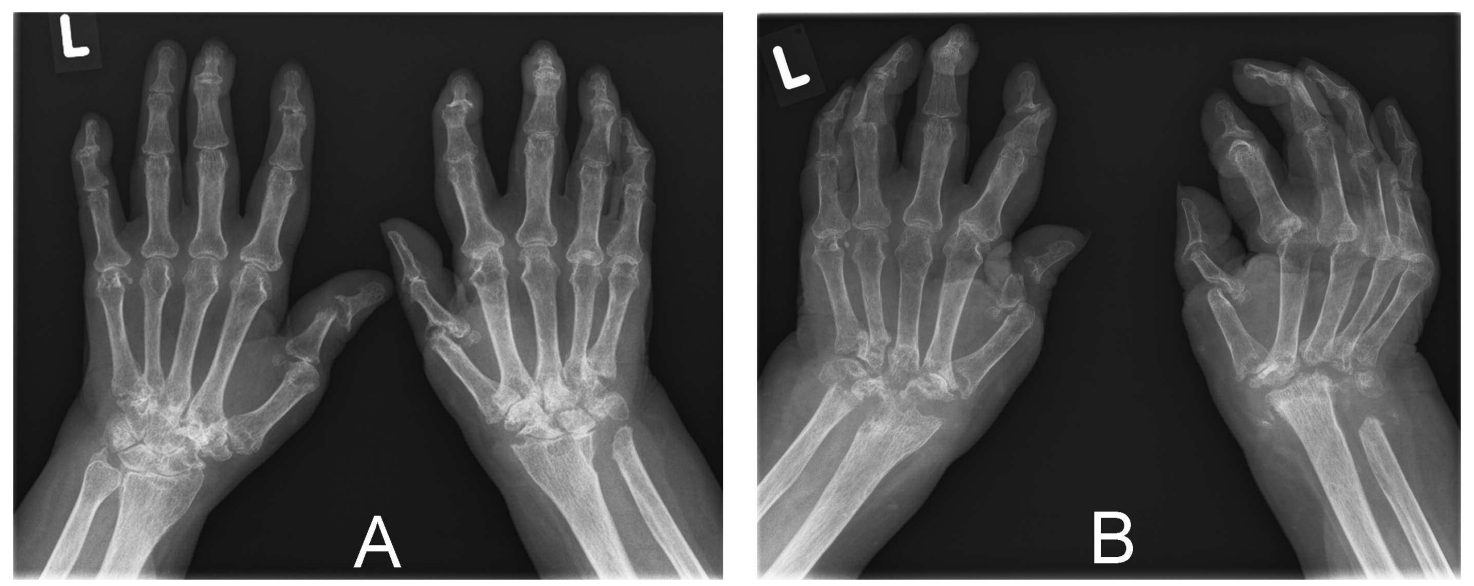

Figure 1. Plain radiographs of both hands from (A) 2012 and (B) 2015 showing severe destruction of nearly all joints and a complete lysis of the right carpus after 3 years with irregular therapy. 